\title{
Çinko Ferrit Nanopartikül ile Modifiye Edilmiş PSf Kompozit Membranların Hazırlanması ve Performanslarının Belirlenmesi
}

\author{
Abdullah Oğuz Can ${ }^{1}$, Emine Özkan², Ahmet Özgür Saf ${ }^{3 *}$ \\ ${ }^{1}$ Milli Eğitim Bakanlığı, Fen Bilimleri Öğretmeni, Konya, Türkiye, (ORCID: 0000-0002-1527-1335), oguzzzcan42@gmail.com \\ 2 Necmettin Erbakan Üniversitesi, BİTAM, Konya, Türkiye, (ORCID: 0000-0001-7924-4304), 00emineozkan00@gmail.com \\ $3^{*}$ Necmettin Erbakan Üniversitesi, Ahmet Keleşoğlu Eğitim Fakültesi, Konya, Türkiye, (ORCID: 0000-0002-6401-5434), aosaf42@gmail.com
}

(İlk Geliş Tarihi Aralık 2020 ve Kabul Tarihi Ocak 2021)

(DOI: 10.31590/ejosat.852822)

ATIF/REFERENCE: Can, A.O., Özkan, E. ve Saf, A.O. (2021). Çinko Ferrit Nanopartikül ile Modifiye Edilmiş PSf Kompozit Membranların Hazırlanması ve Performanslarının Belirlenmesi. Avrupa Bilim ve Teknoloji Dergisi, (22), 159-166.

$\ddot{O} \mathbf{z}$

$\mathrm{Bu}$ çalışmada, hidrotermal sentez yöntemi ile çinko ferrit $\left(\mathrm{ZnFe}_{2} \mathrm{O}_{4}\right)$ nanopartikül sentezlenerek XRD ve FTIR teknikleriyle karakterize edilmiştir. Boş PSf ve farklı kütle oranlarında çinko ferrit içeren nanofiltrasyon membranlar faz değişim metodu ile hazırlanmıştır. Hazırlanan membranlar FESEM ve AFM görüntülerinin incelenmesi, temas açısı, gözeneklilik ölçümleri, saf su akılarının belirlenmesi, kirlenme direnci ile tuz giderimi sonuçları ile morfoloji ve performans açısından karakterize edilmiştir. Çinko ferrit nanoparçacıklarının eklenmesi ile membranların gözenekliliği ve hidrofilikliğinde iyileşmeler gözlenmiş, bunun bir sonucu olarak saf su akısında önemli bir artış elde edilmiştir. Saf su akısı, PSf membran için $1.5 \mathrm{~L} / \mathrm{m}^{2} \mathrm{~h}$ olarak gerçekleşirken, $\% 54.9$ artı̧̧la $\% 2.5$ çinko ferrit içeren kompozit membran için $4.5 \mathrm{~L} / \mathrm{m}^{2} \mathrm{~h}$ olarak bulunmuştur. Membranların tuz giderme performansı $1000 \mathrm{ppm} \mathrm{Na}_{2} \mathrm{SO}_{4}$ çözeltisi kullanılarak incelenmiş ve en iyi performans \% 40.6 tuz giderimi ile $\% 2.5$ çinko ferrit içeren kompozit membranda elde edilmiştir. Ayrıca, membran uygulamalarında önemli bir problem olarak kabul edilen membran kirlenmesi BSA çözeltisi kullanılarak araştırılmışıtı. BSA çözeltisi kullanılmadan önce ve sonraki saf su akılarının değişimi incelenmiştir. $\mathrm{ZnFe}_{2} \mathrm{O}_{4}$ katkılı membranların FRR değerleri, PSf membranın \%56 olan FRR değerinden daha yüksek bulunmuştur. Bu, nanoparçacık eklenmesinin membranın kirlilik önleyici özelliğini önemli ölçüde iyileştirdiğini göstermektedir. Ayrıca, membranların kirlenme direncini daha detaylı incelemek için tersinir kirlenme oranı (Rr), tersinmez kirlenme oranı (Rir) ve toplam kirlenme (Rt) değerleri hesaplanmıştır. Ağırlıkça \% 2.5 çinko ferrit içeren membranın toplam kirlenme ve tersinmez kirlenme oranının PSf membrana kıyasla daha düşük olduğu bulunmuştur. Ayrıca, en yüksek tersinir kirlenme oranı elde edilmiştir. Sonuç olarak, PSf membrana çinko ferrit nanoparçacıkların katılması performansının iyileşmesine katkı sağladığını görülmüştür.

\section{Preparation of PSf Composite Membranes Modified with Zinc Ferrite Nanoparticle and Determination of Their Performance}

\begin{abstract}
In the study, zinc ferrite $\left(\mathrm{ZnFe}_{2} \mathrm{O}_{4}\right)$ nanoparticles were synthesized by the hydrothermal synthesis method and characterized by FTIR and XRD techniques. Blank PSf and nanofiltration membranes containing different mass ratios of zinc ferrite were prepared by phase inversion process. The prepared membranes were characterized in terms of morphology and performance by examining FESEM and AFM images, contact angle, porosity measurements, determination of pure water fluxes, contamination resistance and desalination results. With the addition of zinc ferrite nanoparticles, improvements were observed in the porosity and hydrophilicity of the membranes,
\end{abstract}

* Sorumlu Yazar: aosaf42@gmail.com 
as a result of which a significant increase in pure water flux was obtained. While the pure water flux was realized as $1.5 \mathrm{~L} / \mathrm{m}^{2} \mathrm{~h}$ for PSf membrane, it was found as $4.5 \mathrm{~L} / \mathrm{m}^{2} \mathrm{~h}$ for the composite membrane containing $2.5 \%$ zinc ferrite with an increase of $54.9 \%$. The desalination performance of the membranes was examined by using $1000 \mathrm{ppm} \mathrm{Na} \mathrm{SO}_{4}$ solution and the best performance was obtained on the composite membrane containing $2.5 \%$ zinc ferrite with $40.6 \%$ desalination. In addition, membrane fouling, which is considered to be an important problem in membrane applications, has been investigated using BSA solution. The variation of pure water fluxes before and after using BSA solution was investigated. The blended membranes with $\mathrm{ZnFe}_{2} \mathrm{O}_{4}$ exhibited higher FRR values than the $56 \%$ FRR value of the PSf membrane. This indicates that the addition of nanoparticles significantly improves the antifouling property of the membrane. In addition, reversible fouling ratio $(\mathrm{Rr})$, irreversible fouling ratio (Rir) and total fouling (Rt) values were calculated to examine the fouling resistance of the membranes in more detail. It was found that the total fouling and irreversible fouling ratio of the membrane containing $2.5 \%$ zinc ferrite by weight were lower compared to the PSf membrane. In addition, the highest reversible contamination ratio was obtained. As a result, it has been seen that the addition of zinc ferrite nanoparticles to PSf membrane contributes to the improvement of its performance.

Keywords: Composite membrane, Polysulfone, Zinc ferrite, Pure water flux, Antifouling

\section{Giriș}

İki ortamı birbirinden ayıran membranlar, basınç, sıcaklık, konsantrasyon ve elektriksel potansiyel farkı gibi yürütücü kuvvetler ile maddelerin seçici bir şekilde ayrılmasını sağlayan yarı geçirgen malzemelerdir. Membranlar, çeşitli ayırma işlemlerinde ve günlük yaşamımızda önemli rol oynamaktadırlar. Membranların hazırlanmasında polisülfon (PSf), polyetersülfon (PES), selüloz asetat (CA), poliimit (PI), poliviniliden florür (PVDF), polyamit (PA), polieterimit (PEI) ve poli(fenilen eter eter sülfon) (PEES) gibi birçok polimer maddesi kullanılmaktadır (Ansari vd., 2015). Termal ve mekanik kararlığa, kolay işlenme potansiyeline, çevresel etkilere karşı dayanıklı ve ısıyla bozunmaya karşı uygun dirence sahip olmaları nedeniyle PSf ve PES en yaygın olarak kullanılan polimerlerdir (Nasrollahi vd., 2018) . Ancak bunların yanında PSf ve PES'in hidrofobik özellikte olması, membranları kirlenmeye yatkın hale getirmektedir (Luo vd., 2005). Membran kirlenmesi, kek oluşumu ve gözenek tıkanması da dâhil olmak üzere çeşitli mekanizmalarla akının azalmasına neden olmaktadır (Zhang vd., 2018). Kirlenme ayrıca membranı bozar, uygulama süresini ve seçiciliğini azaltır (Agenson ve Urase, 2007). Kirleticilerin çoğu hidrofobik özellikte olduğundan, membran hidrofilisitesindeki artış kirlenme direncinin artmasına (kirlenmenin azalmasına) neden olmaktadır (Safarpour vd., 2016).

Polimerik membranların hidrofilisitesini ve kirlenme önleyici özelliklerini geliştirmek için farklı prosedürleri içeren birçok yaklaşım bulunmaktadır. Bunlar; nanotaneciklerle polimerlerin karıştırılması (Zinadini vd., 2017), UV ışınlaması (Yu vd., 2006), plazma işlemi (Tyczkowski vd., 2007) ve kimyasal modifikasyon (Han vd., 2011) işlemleridir. Son zamanlarda birçok araştırmacı membrana $\mathrm{Al}_{2} \mathrm{O}_{3}, \mathrm{SiO}_{2}, \mathrm{TiO}_{2}$, $\mathrm{Fe}_{2} \mathrm{O}_{3}$ gibi çeşitli metal oksit nanopartikülleri ekleyerek hidrofilikliği artırmaya ve membran kirlenmesini azaltmaya yönelik çalışmalara odaklanmıştır (Nasrollahi vd. 2018; Safarpour vd., 2016). Metal oksit nanopartiküllerden spinel ferrit (SF) manyetik malzemeler, demir iyonları içeren ve $\mathrm{MFe}_{2} \mathrm{O}_{4}(\mathrm{M}$ $\left.=\mathrm{Mg}^{2+}, \mathrm{Co}^{2+}, \mathrm{Ni}^{2+}, \mathrm{Zn}^{2+}, \mathrm{Fe}^{2+}, \mathrm{Mn}^{2+}, \mathrm{vb}\right)$ genel yapisal formülüne sahip önemli bir kompozit metal oksit sınıfıdır. SF'ler, mükemmel manyetik özellikler, geniş yüzey alanı ve yüzey aktif alanlar, yüksek kimyasal kararlılık, ayarlanabilir şekil ve boyut ile modifiye/işlevselleştirilme kolaylığ $\breve{l}_{1}$ gibi benzersiz fizikokimyasal özelliklere sahiptirler (Reddy ve Yun, 2016). Bu özelliklerinden yararlanılarak Spinel ferrit (SF) manyetik malzemeler içeren membran çalışmaları yapılmıştır. Zareei vd., (2019) yılında yaptıkları çalışmada $\mathrm{CoFe}_{2} \mathrm{O}_{4} / \mathrm{CuO}$ nanopartikülleri kullanarak hazırladıkları PES esaslı kompozit membranların, boş PES membrandan daha yüksek yüzey hidrofilikliğine sahip olduğunu bulmuşlardır. PES içerisinde farklı oranlarda $\mathrm{CoFe}_{2} \mathrm{O}_{4} / \mathrm{CuO}$ karıştırılarak elde edilen membranların saf su akısında $12 \mathrm{~L} / \mathrm{m}^{2} \mathrm{~h}$ 'dan $34.5 \mathrm{~L} / \mathrm{m}^{2} \mathrm{~h}$ 'a varan bir artışa sebep olduğunu, tuz giderim performanslarının $\mathrm{NaCl}$ için \%32'den \%72'ye, $\mathrm{Na}_{2} \mathrm{SO}_{4}$ için \%62'den \%95'e yükseldiğini belirlemişlerdir. Ayrıca membranların kirlenmeye karşı performasının FRR \%90 gibi yüksek bir değere ulaştığını ortaya koymuşlardır. Koulivand vd., (2019) yaptıkları çalışmada $\mathrm{Fe}_{3} \mathrm{O}_{4}$ magnetik nanopartikülleri sentezleyerek (3-aminopropyl) triethoxysilane (APTES) ve/veya dendrimer amin (MDA) ile fonksiyonlandırmışlardır. Elde ettikleri nanokompozit malzemeler ile PES membranlar hazırlayarak membranların saf su geçirgenliği, tuz giderme ve kirlenme performanslarını incelemişlerdir. $\mathrm{Bu}$ çalışma sonucunda \%0.5 PES- $\mathrm{Fe}_{3} \mathrm{O}_{4}-\mathrm{MDA}$ bileşimindeki kompozit membranın en yüksek hidrofiliklik, geçirgenlik, reddetme ve kirlenme önleyici özellikler gösterdiğini ortaya koymuşlardır. Ba-Abbad vd., (2017) tarafından yapılan çalışmada, demir oksit $\left(\alpha-\mathrm{Fe}_{2} \mathrm{O}_{3}\right)$ nanopartiküllerini sol-jel metoduyla sentezleyerek çeşitli tekniklerle karakterize etmişlerdir. Sentezledikleri NP'leri kullanarak faz değişim metodu ile kompozit PSf membranlar elde etmiştirler. Membranların geçirgenlik, gözeneklilik ve gözenek boyutu özelliklerindeki değişmeleri incelemişlerdir. Aynı zamanda NP içeren membranların saf su geçirgenliğinin yaklaşık 3 kat arttığını, aynı şartlarda tuz giderim performansının da iyileştiğini söylemiştir.

$\mathrm{Bu}$ çalışmada, hidrofilik özellikteki $\mathrm{ZnFe}_{2} \mathrm{O}_{4}$ nanopartikül sentezlenerek faz değişim metoduyla kompozit membranlar hazırlanmıştır. Hazırlanan membranların hidrofiliklik, gözeneklilik ve yüzey özellikleri sırasıyla temas açısı, FESEM ve AFM ile incelenerek $\mathrm{ZnFe}_{2} \mathrm{O}_{4}$ ' ün membran üzerine etkisi araştırılmıştır. Ayrıca, hazırlanan kompozit membranların saf su geçirgenliği, tuz giderimi ve kirlenmeye karşı direnç performansları araştırılmıştır.

\section{Materyal ve Metot}

Çalışmada kullanılan polisülfon (Mw: 32,000 g/mol), dimetil-formamid (DMF), sığır serumu albümini (BSA) (Mw: 66 $\mathrm{kD})$, setiltrimetilamonyum bromür (CTAB), $\mathrm{FeCl}_{3} \cdot 6 \mathrm{H}_{2} \mathrm{O}, \mathrm{ZnCl}_{2}$, $\mathrm{Na}_{2} \mathrm{SO}_{4}$ ve $\mathrm{NaOH}$ Sigma-Aldrich firmasından temin edilmiştir. Membran hazırlanırken destek malzemesi olarak holiteks (Hollytex 3329) kullanılmıştır.

\section{1. Çinko Ferrit Sentezi ve Karakterizasyonu}

Çinko ferrit literatüre göre başarıyla sentezlenmiştir (Vural vd., 2016). İlk olarak $35 \mathrm{~mL}$ saf su ile $1 \mathrm{~g}$ setiltrimetilamonyum bromür (CTAB) karıştırılmıştır. Karışımın üzerine $1 \mathrm{~g}$ $\mathrm{FeCl}_{3} .6 \mathrm{H}_{2} \mathrm{O}$ çözeltisi ile stokiyometrik miktarda $\mathrm{ZnCl}_{2}$ çözeltisi eklenmiştir. Saf su ile son hacim $40 \mathrm{~mL}$ ye tamamlandıktan sonra $\mathrm{NaOH}$ çözeltisi kullanılarak karışımın pH'sı 11'e ayarlanmıştır. 
Sonrasında karışım teflon reaktöre alınarak $130{ }^{\circ} \mathrm{C}$ sıcaklıkta 15 saat reaksiyon gerçekleştirilmiştir. Reaksiyon sonunda ürün saf suyla yıkanarak etüvde kurutulmuştur. $\mathrm{ZnFe}_{2} \mathrm{O}_{4}$ nanopartikülün yapısal karakterizasyonu, X-Işını Kırınımı ve FTIR teknikleri kullanılarak yapılmıştır. FT-IR spektrumları ATR probu kullanılarak ölçülmüştür. X-1şını kırınımı (XRD) ölçümleri, 20 ila $70^{\circ}$ arasında $2 \Theta$ tarama aralığında $40 \mathrm{kV}$ hızlanma voltajı ile monokromatik $\mathrm{CuK} \alpha$ radyasyonu $(\lambda=0.154 \mathrm{~nm})$ ile elde edilmiştir.

\subsection{Kompozit membranların hazırlanması}

0,8 gram PSf'ye 4,2 gram DMF eklenerek dökme çözeltisi hazırlandı. Çözelti, oda sıcaklığında 24 saat karıştırıldı. Çözeltiden gaz kabarcıklarını çıkarmak için ultrasonikasyona tabi tutuldu. Sonikasyon işlemi esnasında PSf'ye göre ağırlıç̧a $\% 0.5$, $\% 1.5, \% 2.5$ ve $\% 3.5$ çinko ferrit eklenerek farklı bileşime sahip dökme çözeltileri hazırlandı. Sonrasında dönel kaplama (spin couting) cihazı kullanılarak holytex yüzeyi dökme çözeltileriyle kapland1. Kaplanan holytex su banyosuna daldırılarak faz değişim işlemi gerçekleştirildi ve kompozit membranlar elde edildi. Membranlar, kurutularak kullanıma hazır hale getirildi. Elde edilen membranlar ve dökme çözeltileri Şekil 1'de gösterildiği gibidir. Ayrıca, hazırlanan membranların içerikleri Tablo 1.'de verilmiştir.
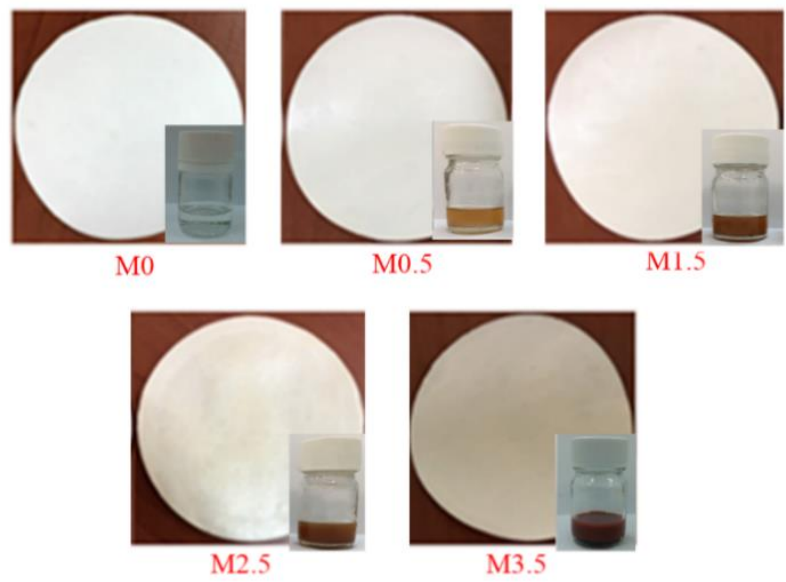

Şekil 1. Farklı içeriğe sahip dökme çözeltileri ve elde edilen membranlar

Tablo 1. Hazırlanan membranların bileşimleri

\begin{tabular}{cccc}
\hline Membran & PSf (\%) & DMF (\%) & ZnFe $_{2} \mathbf{O}_{4}(\%)$ \\
\hline M0 & 16 & 84 & - \\
\hline M0.5 & 16 & 84 & 0.5 \\
\hline M1.5 & 16 & 84 & 1.5 \\
\hline M2.5 & 16 & 84 & 2.5 \\
\hline M3.5 & 16 & 84 & 3.5 \\
\hline
\end{tabular}

\subsection{Membranların Karakterizasyonu}

Hazırlanan membranların karakterizasyonunda Alan Emisyonlu Taramalı Elektron Mikroskobu (FESEM), Atomik Kuvvet Mikroskobu (AFM) kullanılmış ayrıca, gözeneklilik ve temas açısı ölçümleri yapılmıştır. Hazırlanan membranların performansları saf su geçirgenliği, tuz giderme ve kirlenme direnci deneyleri ile belirlenmiştir.
Hazırlanan membranların enine kesit görüntüleri FESEM (Zeiss Gemini SEM 500) ile $1.0 \mathrm{kV}$ ve $10.0 \mathrm{k}$ büyütmede elde edilmiştir. Görüntülenecek membranlar Au/Pt ile kaplanarak daha iletken olmaları sağlanmıştır.

AFM (Park Sistemleri-XE7 modeli) ölçümleri; membranların yüzey pürüzlülüklerinin belirlenmesi amacıyla $10 \mu \mathrm{m} \times 10 \mu \mathrm{m}$ alanında, temassız modda (non contact mode) ve $1 \mathrm{~Hz}$ tarama hızında gerçekleştirilmiştir.

Membranların hidrofilik davranışlarını belirlemek amacıyla temas açısı ölçümleri yapılmıştır. Bu amaçla $5 \mu \mathrm{L}$ su membran yüzeyine damlatılarak statik temas açıları bilgisayarlı ortamda ölçülmüştür.

Membranların toplam gözenekliliği gravimetrik metotla aşağıdaki denklem kullanılarak hesaplanmıştır (Zinadini vd., 2014a)

$\varepsilon=\frac{\omega_{1}-\omega_{2}}{A x l x d_{w}}$

Formülde; $\varepsilon$ : Toplam porozite; $\omega_{1}$ : Islak membran kütlesi (g); $\omega_{2}$ : Kuru membran kütlesi (g); $A$ : Aktif membran alanı $\left(\mathrm{cm}^{2}\right) ; l$ : Membran kalınlığ $1(\mathrm{~cm}) ; d_{w}$ : Suyun yoğunluğu $\left(\mathrm{g} / \mathrm{cm}^{3}\right)$ 'dur.

Saf su geçirgenliği, tuz giderimi ve kirlenme direnci ile ilgili çalışmaların tamamı 0,00146 $\mathrm{m}^{2}$ yüzeyli Sterlitec HP4750 Deadend (kör-uç) filtrasyon sistemi kullanılarak gerçekleştirilmiştir. Çalışmalarda membranlar 30 dakika süreyle 5 barda sıkıştırılarak akının sabit değere ulaşması sağlanmıştır. Sonrasında basınç 3 bara düşürülerek çalışmalar gerçekleştirilmiştir.

Membranın saf su geçirgenliğinin belirlenmesi için 90 dakika boyunca her 5 dakikada bir toplanan su miktarı ölçülmüş ve aşağıdaki akı eşitliği kullanılarak hesaplama yapılmıştır.

$J=\frac{M}{A \Delta t}$

eşitlikte; $J$ : Su akısını $\left(\mathrm{kg} / \mathrm{m}^{2} \mathrm{~h}\right), M$ : Su kütlesini $(\mathrm{kg}), A$ : Aktif membran alanını $\left(\mathrm{m}^{2}\right), \Delta t$ : Ölçüm süresini $(\mathrm{h})$ göstermektedir.

Membranların tuz giderme (reddetme) performanslarını belirlemek için 1000 ppm $\mathrm{Na}_{2} \mathrm{SO}_{4}$ çözeltisi kullanılmıştır. 90 dakikalık süre sonunda süzüntünün iletkenlik ölçümleri yapılarak aşağıdaki formülle tuz reddetme oranı hesaplanmıştır:

$R(\%)=\left(1-\frac{C_{p}}{C_{f}}\right) \times 100$

Formülde; $R$ : Reddetme yüzdesi; $C_{p}$ : süzüntü derişimini; $C_{f}$ : besleme derişimini ifade etmektedir.

Membranın kirlenmeye karşı gösterdiği dirençle ilgili çalışmalarda 60 dakika boyunca membrandan önce saf su, sonra kirletici olarak 600 ppm BSA çözeltisi geçirilmiştir. Daha sonra membranlar temizlenerek ve aynı şartlarda 60 dakika saf su geçirilerek deney tamamlanmıştır. Bu işlemlerdeki $J_{w, 1}\left(\mathrm{~kg} / \mathrm{m}^{2} \mathrm{~h}\right)$, $J_{p}\left(\mathrm{~kg} / \mathrm{m}^{2} \mathrm{~h}\right)$ ve $J_{w, 2}\left(\mathrm{~kg} / \mathrm{m}^{2} \mathrm{~h}\right)$ ile simgelenen akılar hesaplanarak ak1 geri kazanım oranı (flux recovery ratio, FRR), toplam kirlenme oranı (total fouling ratio, Rt), tersinir kirlenme (reversible fouling ratio, Rr) ve tersinmez kirlenme (irreversible fouling ratio, Rir) aşağıdaki eşitlikler kullanılarak bulunmuştur.

$F R R=\left(\frac{J_{w, 2}}{J_{w, 1}}\right) \times 100$
$R_{t}(\%)=1-\left(\frac{j_{p}}{j_{w, 1}}\right) \times 100$ 
$R_{r}(\%)=\left(\frac{j_{w, 2}-j_{p}}{j_{w, 1}}\right) \times 100$

$R_{\text {ir }}(\%)=\left(\frac{j_{w, 1}-j_{w, 2}}{j_{w, 1}}\right) \times 100=R_{t}-R_{r}$

eşiliklerde; $J_{p}$ : BSA geçişi sırasındaki akıyı $\left(\mathrm{kg} / \mathrm{m}^{2} \mathrm{~h}\right), J_{w, 1}$ : İlk saf su akısını $\left(\mathrm{kg} / \mathrm{m}^{2} \mathrm{~h}\right), J_{w, 2}$ : BSA çözeltisi geçirildikten sonra temizlenmiş membranın saf su akısını $\left(\mathrm{kg} / \mathrm{m}^{2} \mathrm{~h}\right)$ göstermektedir (Zinadini ve ark., 2014b).

\section{Araştırma Sonuçları ve Tartışma}

\subsection{FT-IR ve XRD Karakterizasyonu}

Sentezlenen çinko ferrit nanoparçacığına ait FT-IR spektrumu Şekil 2a'da verilmiştir. Şekil 2a incelendiğinde $550 \mathrm{~cm}^{-1}$ görülen metal-oksijen piki $\mathrm{ZnFe}_{2} \mathrm{O}_{4}$ 'e ait karakteristik piktir (Xie vd., 2013). $3450 \mathrm{~cm}^{-1}$ dolayında gözlemlenen geniş bant yüzey hidroksillerine ait $-\mathrm{OH}$ gerilme titreşimlerinden kaynaklanmaktadır (Oliveira vd., 2009).
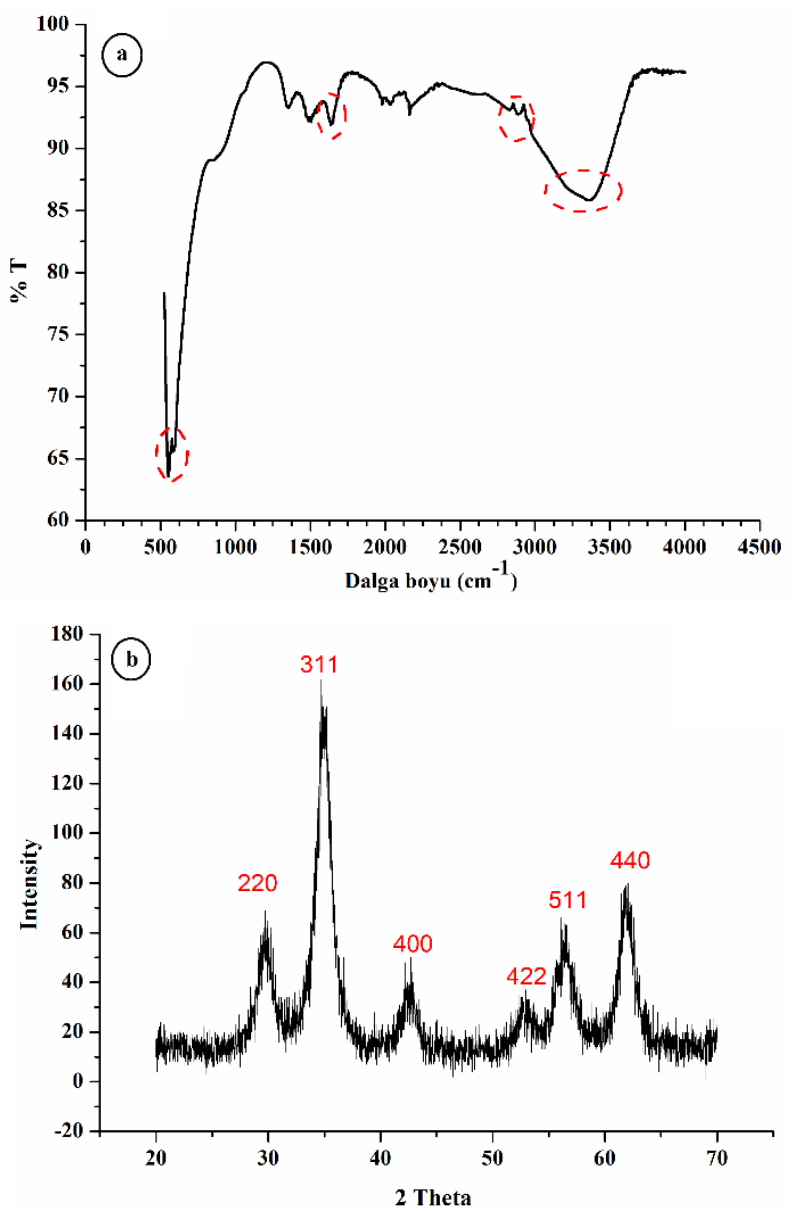

Şekil 2. $\mathrm{ZnFe}_{2} \mathrm{O}_{4}$ 'ün a) FT-IR spektrumu, b) XRD spektrumu

Ayrica, 2890 ve $2955 \mathrm{~cm}^{-1}$ 'de iki bant, $\mathrm{ZnFe}_{2} \mathrm{O}_{4}$ nanopartiküllerinin yüzeyindeki metal iyonları ile sürfaktandan kaynaklanan $-\mathrm{CH}_{2}$ grubunun asimetrik ve simetrik germe modlarından meydana gelmektedir (Manohar vd., 2019). 1593 $\mathrm{cm}^{-1}$ deki pikin, COO-'nun simetrik germe modundan kaynaklanabileceği düşünülmektedir.

$\mathrm{ZnFe}_{2} \mathrm{O}_{4}$ nanopartiküllerinin XRD spektrumu Şekil 2b'de gösterilmiştir. Şekil $2 \mathrm{~b}$ incelendiğinde $\mathrm{ZnFe}_{2} \mathrm{O}_{4}$ 'ün kırınım piklerinin $2 \theta=29.9,35.3,42.8,53.1,56.6$ ve 62 şeklinde olduğu görülmektedir. Piklere ait düzlemsel değerler sırasıyla (220),
(311), (400), (422), (511) ve (440) şeklindedir. Elde edilen bu değerler (Yang vd., 2015) yaptığı çalışma ile uyumludur.

\subsection{FT-IR ve XRD Karakterizasyonu}

\subsubsection{Temas açısı}

Yüzey hidrofilikliği; akı ve kirlenmeye karşı direnç gibi membran performansını etkileyen en önemli özelliklerinden biridir (Vatanpour vd. 2020). Farklı bileşimdeki membranların temas açıları Şekil 3'te verilmiştir. Şekil 3'de görüldüğü gibi boş PSf membran (M0) en yüksek temas açısı $\left(92^{\circ}\right)$ değerine sahiptir. Membranlara ağırlıç̧a $\% 0.5, \% 1.5$ ve $\% 2.5$ çinko ferrit ilavesi ile membran yüzeylerinin temas açıları sirasıyla 90, 83 ve 80 'e düşmüştür. Temas açısındaki bu düşüş, faz değişimi sırasında membran çözeltisi içerisinde bulunan ve yüksek yüzey serbest enerjisine sahip hidrofilik özellikteki çinko ferrit nanoparçacıkların membranın üst tabakasına göç etmesinden kaynaklanmaktadır (Arumugham vd., 2019).
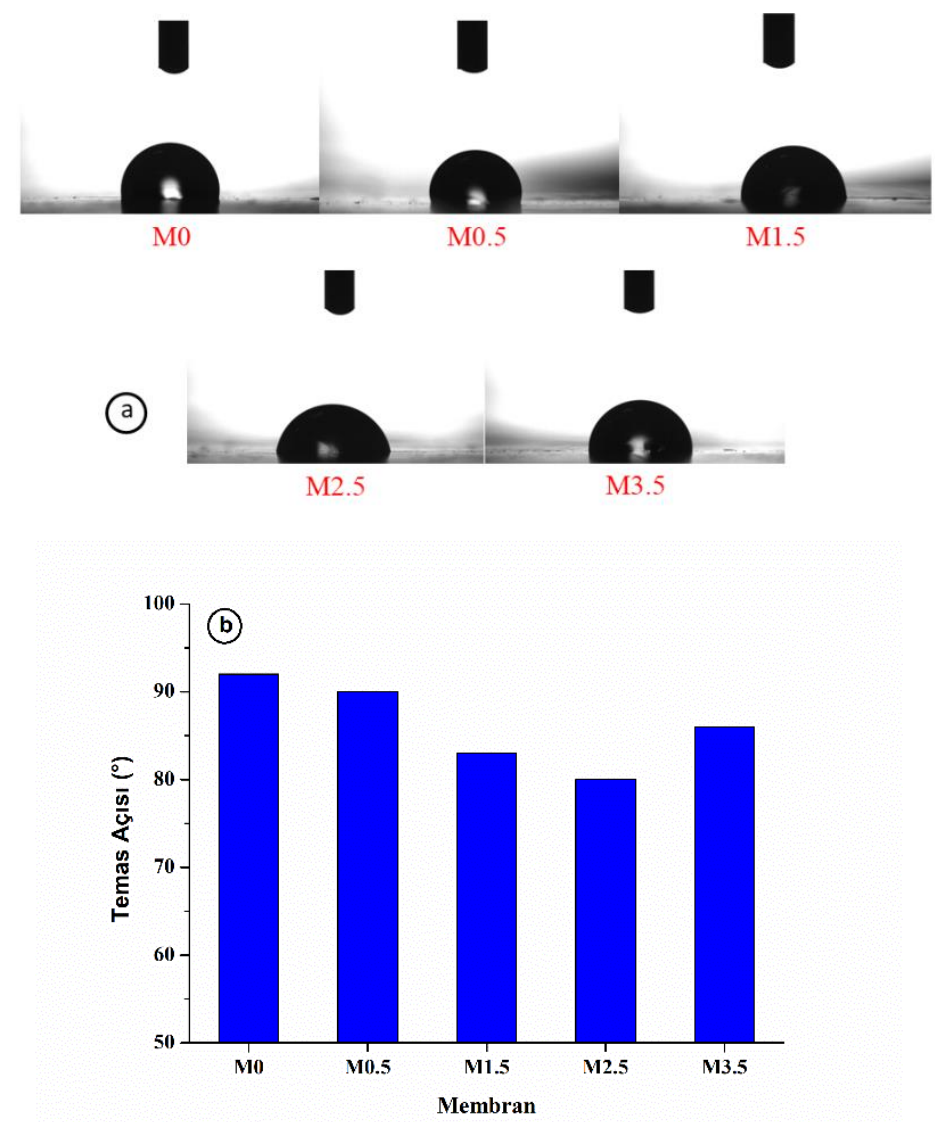

Şekil 3. Membranların; a) Temas açısı görüntüleri, b) Membranların temas açısı değişimi

Ayrica, membran yüzeyinde hidrofilik nanokompozit malzemenin varlığı, membran yüzeyi ile su molekülleri arasında hidrojen bağı oluşumuna neden olarak temas açısını azaltmakadır (Seyyed Shahabi vd., 2020). Ancak membrana en yüksek madde miktarı olan \%3.5 çinko ferrit ilave edilmesiyle temas açısının 86 'ya yükseldiği görülmektedir. $\mathrm{Bu}$ durum nanopartiküllerin belirli bir değerden sonra bir araya toplanarak hidrofilikliğe daha fazla katkıda bulunamadıkları şeklinde düşünülebilir.

\subsubsection{Gözeneklilik}

Kompozit membranların gözenekliliği eklenen çinko ferrit miktarına bağlı olarak PSf ve ağırlıkça $\% 0.5, \% 1.5, \% 2.5$ ve $\% 3.5$ çinko ferrit içeren membranlar için sırasıyla \%16,4; \% 21,3; \% 
25,4; \% 27,1 ve \% 18,5 olarak bulunmuştur. Şekil 4'de membran bileşimine katılan çinko ferrit miktarı arttıkça gözenekliliğin arttığı, ağırlıç̧a \%3.5 çinko ferrit eklenmesiyle gözenekliliğin azaldığı görülmektedir. Membran gözenekliliği, polimer çözeltisinin faz inversiyonu sırasında kütle transferine bağımlıdır (Hong ve He, 2014). Hidrofilik nanopartiküllerin varlığı çözücü/çözücü olmayan madde değişimini daha hızlı hale getirir ve faz inversiyon işlemi sırasında gözenekliliğin artmasına neden olur (Chung vd., 2017). Diğer taraftan nanoparçacıkların belirli bir orandan fazla olması (\%3.5 çinko ferrit eklenmesi) dökme çözeltisinin viskozitesini artırarak kütle değişim hızının azalmasina neden olur (Hosseini vd., 2018). Bu durumun nanopartiküllerin belirli bir miktardan sonra membranın gözenek yapısını bozmaya başlaması ya da farklı gözenek boyutlarının oluşmasından kaynaklandığı düşünülmektedir (Luo vd., 2012).

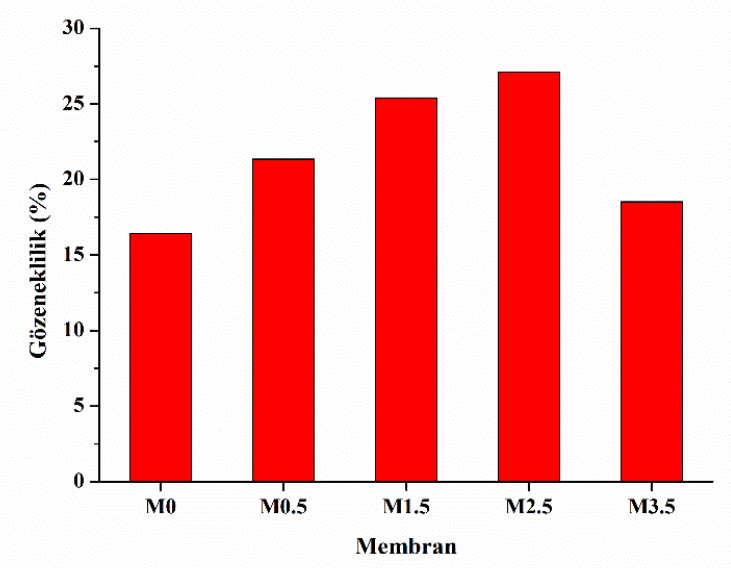

Şekil 4. PSf ve PSf/ZnFe ${ }_{2} \mathrm{O}_{4}$ membranların gözeneklilikleri

\subsubsection{FESEM analizi}

Farklı miktarda çinko ferrit ile hazırlanmış PSf $/ \mathrm{ZnFe}_{2} \mathrm{O}_{4}$ membranların FESEM ile alınmış kesit görüntüleri Şekil 5'te verilmiştir. Çinko ferrit ile hazırlanan membranların yapıları birbirine benzerlik göstermektedir. Ancak \%2.5 luk çinko ferrit içeren membran yapısının daha büyük gözenekli ve göz yaşı şeklinde makro boşluklu yapıdan oluştuğu görülmektedir. $\mathrm{Bu}$ yapının oluşmasında faz değişim kinetiği önemli bir etkiye sahiptir. Faz dönüşümü sırasında çinko ferrit nanopartikülleri PSf'ye göre su ile daha fazla etkileşimde olduğundan, membran içerisine hidrofilik nanopartikül eklenmesi suyun difüzyon hızını artırır. Difüzyon hızının gözenek boyutu ve membran gözenekliliğini iyileştirdiği bilinmektedir (Moradihamedani vd., 2014). Yüksek miktarda çinko ferrit içeren membranlarda (ağırlıkça \%3.5 çinko ferrit) polimerik çözeltilerin viskozitesi de artar. Viskozite değerleri tam olarak ölçülmemesine rağmen, viskozitenin artması, çözücü ve çözücü olmayan maddenin değişim hızını düşüreceğinden gözeneklerin yapısının bozulmasına neden olduğu düşünülmektedir.

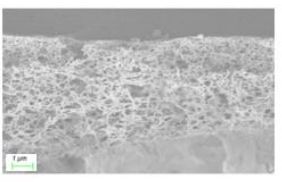

M0

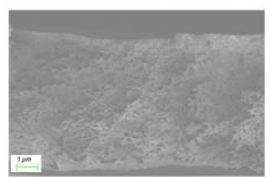

M0.5

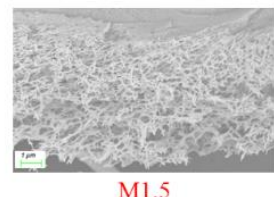

M1.5
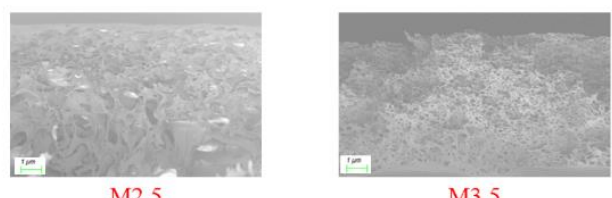

M3.5

Şekil 5. Hazırlanan membranların kesitsel FESEM görüntüleri

\subsection{4. $A F M$}

Hazırlanan membranların üç boyutlu AFM görüntüleri alınarak ortalama pürüzlülük değerleri belirlenmiştir. Şekil 6'daki üç boyutlu AFM görüntülerinde parlak alanlar yükseltileri, karanlık alanlar ise gözenekleri göstermektedir. Ağırlıkça \%2.5'luk membranda hidrofilik nanokompozit malzemenin varlığı membranın sahip olduğu gözenekleri artırmıştır. Çinko ferrit miktarının artışıyla birlikte membranların üst yüzeyinin ortalama pürüzlülük değeri (Ra) artarak sırasıyla 17.1, 33, 42.8, 90.8 ve 102 şeklinde bulunmuştur. Bu artışın, membran oluşurken faz değişimi sırasında su ile DMF arasındaki hızlı yer değişiminden kaynaklandığı düşünülmektedir.

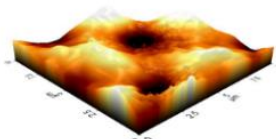

M0

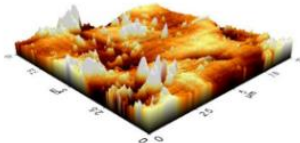

M0.5

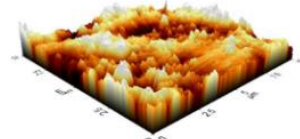

M1.5

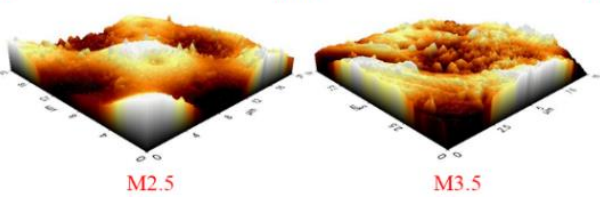

Şekil 6. Hazırlanan membranların AFM görüntüleri

\subsection{Kompozit Membranların Performansları}

\subsubsection{Saf su akıst}

Hazırlanan tüm membranlar için ortalama akı değerleri Şekil 7'de gösterilmiştir. Şekil 7'de çinko ferrit ile katkılanmış membranların saf su akılarının boş PSf membranın saf su akısından daha yüksek olduğu görülmektedir. PSf membranın akı değeri $1,5 \mathrm{~kg} / \mathrm{m}^{2} \mathrm{~h}$ iken kütlece $\% 2.5$ çinko ferrit içeren membranın akısı en yüksek değer olan $4,5 \mathrm{~kg} / \mathrm{m}^{2} \mathrm{~h}$ 'a yükselmiştir. Akıdaki bu artış membran hidrofilikliği ve membran gözenekliliği ile açıklanabilir (Hosseini vd., 2018). Membran yüzeyinin hidrofilikliğinin artması, membranın 1slanabilirliğini artırarak su moleküllerinin membran yüzeyine ve matrisine daha fazla geçmesine yol açar (Zareei ve Hosseini 2019). 


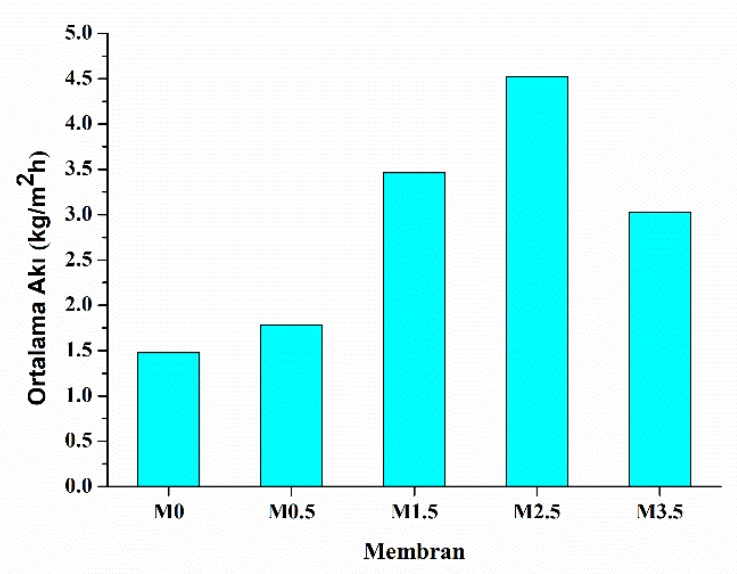

Şekil 7. Hazırlanan membranların ortalama akılart

Şekil 7'de görüldüğü gibi $\mathrm{ZnFe}_{2} \mathrm{O}_{4}$ miktarı $\% 3.5$ olduğunda ak1 değeri 3.30'a düşmüştür. $\mathrm{Bu}$ durum, ağırlıkça $\% 3.5 \mathrm{ZnFe}_{2} \mathrm{O}_{4}$ eklendiğinde membranın hidrofilikliğinin artmasına rağmen membran gözenekliliğindeki düşüşten kaynaklanmaktadır. Bu azalma daha yoğun ve daha az gözenekli membran yapısının oluşmasını sağlayarak akının düşmesine neden olmaktadır.

\subsubsection{Tuz reddetme}

Membranların ayırma performansları çeşitli tuz çözeltilerinin kullanılmasıyla belirlenebilir. Şekil 8'de farklı miktarda çinko ferrit içeren membranların $\mathrm{Na}_{2} \mathrm{SO}_{4}$ tuzunu reddetme değerleri verilmiş̧tir. PSf membranın tuz reddetme oranı \%11.6 iken, bu oran $\mathrm{PSf} / \mathrm{ZnFe}_{2} \mathrm{O}_{4}$ membranlarda artarak \%40.6'ya ulaşmışır. Nanopartikül miktarının artmasıyla ayırma verimliliğindeki artışın ana nedeni negatif yüklü membranlar tarafindan tuz moleküllerinin Donnan dışlanmasından kaynaklanıyor olmasıdır Ayrıca, nanopartikül katkılı hidrofilik yüzeye sahip membranlar, iyi tuz giderimi ile birlikte membran yüzeyinde kirletici birikiminin azalmasına yol açar. Bunun nedeni, hidrofilik yüzeydeki su tabakasının membran yüzeyine yaklaşan iyonları uzaklaştırarak membran tuz reddini iyileştirmesi ve konsantrasyon polarizasyonunu azaltması olarak ifade edilmiştir (Zareei ve Hosseini 2019).

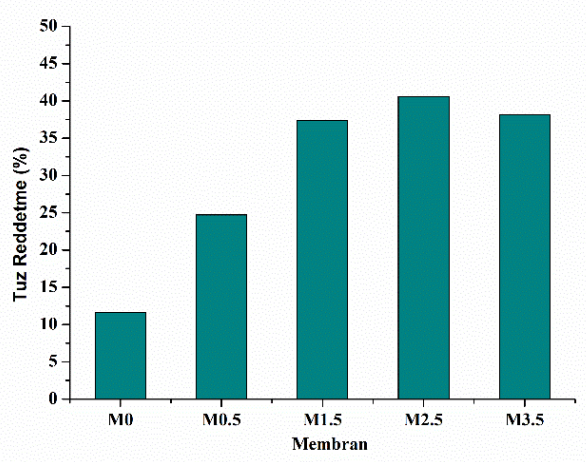

Şekil 8. Membranların $\mathrm{Na}_{2} \mathrm{SO}_{4}$ tuzunu reddetme oranlart

\subsubsection{Kirlenmeye karşı direnç}

Membran kirlenmesi, membran uygulamalarını sınırlayan, akının azalmasına, bakım maliyetlerinin artmasına ve membran yüzeyinin bozulmasına neden olan en önemli problem olarak kabul edilmektedir (Jalali vd., 2016).

PSf ve $\mathrm{ZnFe}_{2} \mathrm{O}_{4}$ katkılı membranların BSA çözeltisi kullanılmadan önce ve sonraki saf su akılarının zamanla değişimi Şekil 9a'da verilmiştir. Başlangıçta saf su ile yapılan ölçümlerde akının yüksek olduğu, BSA filtrasyonundan sonra saf su akısında düşüşler olduğu görülmüştür. Akı düşüşü en fazla PSf membranda olurken, çinko ferrit içeren membranlardaki akı düşüşü daha az olmuştur. Buda nanopatirküllerin membran kirlenmesini önlemedeki etkisini açıkça göstermektedir. Bu etki hazırlanan membranların hidrofilik özelliği ile ilişkilendirilebilir. Şekil 9b'de gösterilen akı geri kazanım oranının (FRR) sayısal değeri, membranın kirlenmeye karşı direnci ile orantılıdır. Çinko ferrit katkılı PSf membranların FRR değerleri, PSf membranın \%56 olan FRR değerinden daha yüksektir. Bu durum nanopartikül eklenmesinin membranın kirlilik önleyici yapısını önemli ölçüde iyileștirdiğini göstermektedir. En yüksek FRR değeri \% 89 ile ağırlıkça \%2.5 çinko ferrit katkılı membran için elde edilmiştir. Bunun sebebi su moleküllerinin hidrofilik membran yüzeyi tarafindan adsorbe edilmesi ve ince bir su tabakası oluşturarak proteinin tutulmasını önlemesidir (Zinadini vd., 2014a).
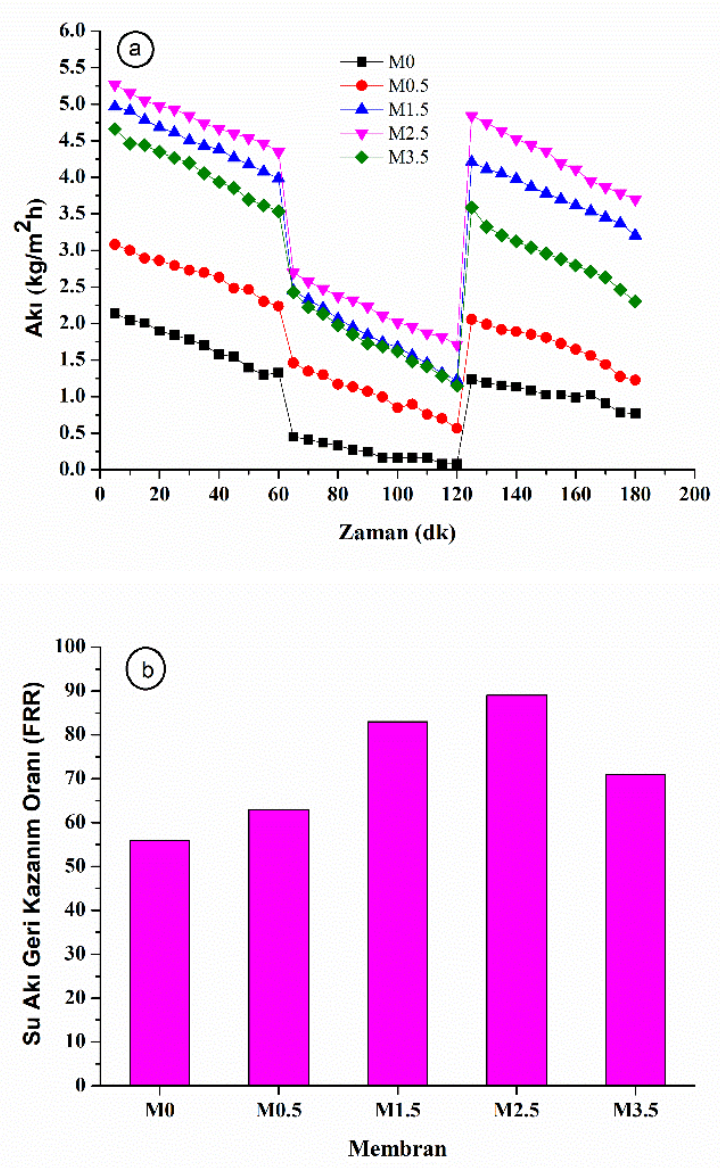

Şekil 9. a) Su-BSA-su ortamlarındaki akı değisşim grafiği, b) Su akısl geri kazanım oranlarl

FRR değişiklikleri, hazırlanan membranların temas açısı ve hidrofilikliği ile tam olarak uyumludur (Koulivand vd., 2019). Daha fazla hidrofilik yüzeye sahip olan membran, daha düşük 
kirlenme ve daha yüksek geri kazanım oranı sunmaktadır (Daraei vd. 2013).

Membranın kirlenme direncini daha detaylı incelemek için tersinir kirlenme oranı $(\mathrm{Rr})$, tersinmez kirlenme oranı (Rir) ve ikisinin toplanmasıyla elde edilen toplam kirlenme (Rt) değerleri hesaplanmıştır. Çinko ferrit katkılı membranların toplam kirlenme oranı (Rt) ve tersinmez kirlenme oranları boş PSf membrana kıyasla daha düşüktür. Şekil 10'daki sonuçlar, toplam kirlenme (Rt) ve tersinmez kirlenmenin PSf ve \%2.5 çinko ferrit içeren membran için sırasıyla $\% 80$ den $\% 55$ ve $\% 45$ den $\% 15$ e düştüğünü göstermektedir. Boş PSf ve \%2.5 çinko ferrit için tersinir kirlenme sırasıyla $\% 35$ ve $\% 45$ olarak hesaplanmıştır. Tersinir kirlenme, membran yüzeyindeki konsantrasyon polarizasyonundan kaynaklanmaktadır ve kolayca giderilebilmektedir. Tersinmez kirlenme ise kirleticilerin membran yüzeyinde adsorpsiyon/desorpsiyonu şeklinde olur. Tersinmez kirlenme membranın hidrofobik yapısından kaynaklanır ve yüzey hidrofilikliğinin geliştirilmesiyle giderilebilir. Yani membran hidrofilikliğindeki artış membran kirliliğini azaltır.

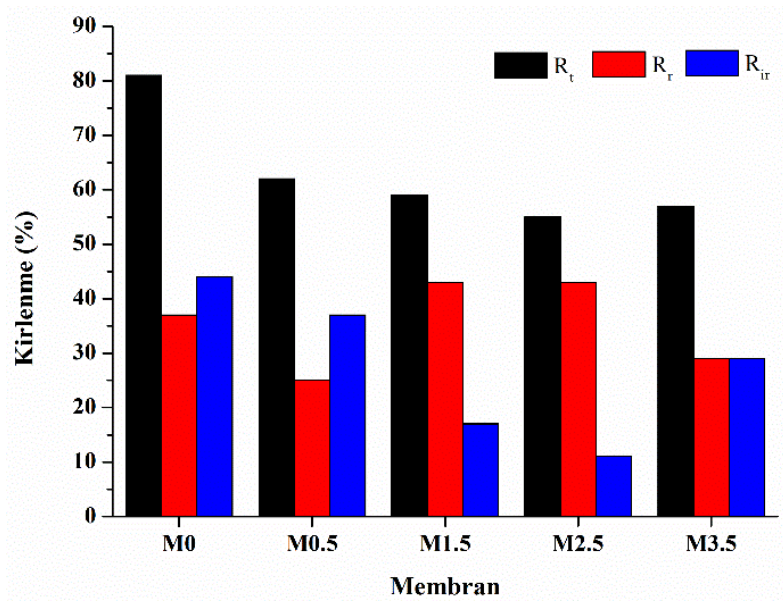

Şekil 10. Hazırlanan membranların kirlenme direnci parametreleri

$\mathrm{PSf} / \mathrm{ZnFe}_{2} \mathrm{O}_{4}$ membranların PSf membrana kiyasla daha gelişmiş kirlenme önleyici özellikleri, çinko ferrit içeren membranların daha az temas açısı ve daha fazla hidrofilikliğinden kaynaklanmaktadır. \%3.5 lik membranda pürüzlülük artarken hidrofiliklikteki azalma yüzey kirliliğinin artmasına neden olmuştur. Bidsorkhi vd., (2016) yılında yaptıkları çalışmada membranların yüksek pürüzlülük değerlerine rağmen, eklenen nanopartiküllerin hidrofilikliği arttırarak yüzey pürüzlülüğüne baskın geldiğini belirtmiştir. Sonuç olarak eklenen çinko ferrit nanopartiküllerin PSf membranının özelliklerinin iyileştirilmesi ve membran performansı üzerinde büyük bir etkisi olduğu görülmektedir.

\section{Sonuç}

Çalışmada $\mathrm{ZnFe}_{2} \mathrm{O}_{4} \quad$ nanopartikül sentezlenerek nanopartikülün membran uygulamalarına yaptığı katk1 araştırılmıştır. $\mathrm{Bu}$ doğrultuda, faz değişim metoduyla faklı miktarda çinko ferrit içeren PSf kompozit membranlar hazırlanarak saf su, tuz ve BSA çözeltileri ile membran performansları araştırılmıştır. Hazırlanan membranların AFM, FESEM, temas açısı ve gözeneklilik ölçümleri ile karakterizasyonları yapılarak şu sonuçlara ulaşılmıştır.

- $\mathrm{ZnFe}_{2} \mathrm{O}_{4}$ katkılı membranların saf su geçirgenliği PSf membrandan daha yüksek bulunmuştur. Özellikle ağırlıkça \%2.5 nanopartikül içeren membranın PSf'ye göre saf su akısında yaklaşık 3 kat iyileşme gözlenmiştir. Bu durumun nanopartikül içeren membranın gösterdiği hidrofilik özellikten ve gözeneklilikten kaynaklandığı belirlenmiştir.

- PSf/ZnFe $2 \mathrm{O}_{4}$ membranların $\mathrm{Na}_{2} \mathrm{SO}_{4}$ çözeltisi ile tuz reddetme performansları incelenmiştir. \%2.5 bileşime sahip kompozit membranın en yüksek tuz reddetme oranı \%40.6 olarak bulunmuştur.

- Membranların kirlenme direncinin belirlenmesi için su ve BSA kullanılarak yapılan çalışmalarda, sistemden BSA çözeltisi geçirildikten sonra çinko ferrit içeren membranlardaki saf su geçirgenliğinin PSf membrandan daha yüksek olduğu görülmüştür. Buda çinko ferrit içeren membranların daha az kirlendiğini ve nanopartiküllerin membran kirlenmesini önlemedeki rolünü açıkça göstermektedir.

- FRR değeri PSf membran için \%56 iken ağırlıkça \%2.5 nanopartikül içeren membran için \%89 bulunmuştur. Bu sonuç \%2.5'luk nanopartikül içeren membranın kirlenmeye karş1 diğerlerinden daha dirençli olduğunu göstermiştir.

- Membranların kirlenme direncini daha detaylı belirlemek için $\mathrm{Rr}$, Rir ve Rt değerleri hesaplanmıştır. Yapılan hesaplamalarda toplam kirlenme (Rt) ve tersinmez kirlenme oranlarının (Rir) boş PSf membrana kıyasla daha düşük olduğu, bunun yanında tersinir kirlenmenin diğerlerinden büyük olması nedeniyle kirlenmenin az olduğu ve membranın yıkanarak tekrar kullanılabileceğini ortaya koymaktadır.

\section{Kaynakça}

Agenson, K.O., \& Urase, T. (2007). "Change in membrane performance due to organic fouling in nanofiltration (NF)/reverse osmosis (RO) applications", Separation and Purification Technology, 55(2), 147-156.

Ansari, S., Moghadassi, A.R., \& Hosseini, S.M. (2015). "Fabrication of novel poly(phenylene ether ether sulfone) based nanocomposite membrane modified by $\mathrm{Fe}_{2} \mathrm{NiO}_{4}$ nanoparticles and ethanol as organic modifier", Desalination, 357, 189-196.

Arumugham, T., Amimodu, R.G., Kaleekkal, N.J., \& Rana, D. (2019). "Nano $\mathrm{CuO} / \mathrm{g}-\mathrm{C}_{3} \mathrm{~N}_{4}$ sheets-based ultrafiltration membrane with enhanced interfacial affinity, antifouling and protein separation performances for water treatment application", Journal of Environmental Sciences (China), 82, 57-69.

Ba-Abbad, M.M., Mohammad, A.W., Takriff, M.S., Rohani, R., Mahmoudi, E., Faneer, K.A., \& Benamo, A. (2017). "Synthesis of iron oxide nanoparticles to enhance polysulfone ultrafiltration membrane performance for salt rejection", Chemical Engineering Transactions, 56(1), 1699-1704.

Bidsorkhi, H.C., Riazi, H., Emadzadeh, D., Ghanbari, M., Matsuura, T., Lau, W.J., \& Ismail, A.F. (2016). "Preparation and characterization of a novel highly hydrophilic and antifouling polysulfone/nanoporous $\mathrm{TiO}_{2}$ nanocomposite membrane", Nanotechnology, 27(41), 415706. 
Chung, Y.T., Mahmoudi, E., Mohammad, A.W., Benamor, A., Johnson, D., \& Hilal, N. (2017). "Development of polysulfone-nanohybrid membranes using $\mathrm{ZnO}-\mathrm{GO}$ composite for enhanced antifouling and antibacterial control", Desalination, 402, 123-132.

Daraei, P., Madaeni, S. S., Ghaemi, N., Khadivi, M. A., Astinchap, B., \& Moradian, R. (2013). "Fouling resistant mixed matrix polyethersulfone membranes blended with magnetic nanoparticles: Study of magnetic field induced casting", Separation and Purification Technology, 109, 111-121.

Han, M. J., Baroña, G. N. B., \& Jung, B. (2011). "Effect of surface charge on hydrophilically modified poly(vinylidene fluoride) membrane for microfiltration", Desalination, 270(1-3), 7683.

Hong, J., \& He, Y. (2014). "Polyvinylidene fluoride ultrafiltration membrane blended with nano- $\mathrm{ZnO}$ particle for photocatalysis self-cleaning", Desalination, 332(1), 67-75.

Hosseini, S. M., Amini, S. H., Khodabakhshi, A. R., Bagheripour, E., \& Van der Bruggen, B. (2018). "Activated carbon nanoparticles entrapped mixed matrix polyethersulfone based nanofiltration membrane for sulfate and copper removal from water", Journal of the Taiwan Institute of Chemical Engineers, 82, 169-178.

Jalali, A., Shockravi, A., Vatanpour, V., \& Hajibeygi, M. (2016). "Preparation and characterization of novel microporous ultrafiltration PES membranes using synthesized hydrophilic polysulfide-amide copolymer as an additive in the casting solution", Microporous and Mesoporous Materials, 228, 113.

Koulivand, H., Shahbazi, A., \& Vatanpour, V. (2019). "Fabrication and characterization of a high-flux and antifouling polyethersulfone membrane for dye removal by embedding $\mathrm{Fe}_{3} \mathrm{O}_{4}$-MDA nanoparticles", Chemical Engineering Research and Design, 145, 64-75.

Luo, M. L., Zhao, J. Q., Tang, W., \& Pu, C. S. (2005). "Hydrophilic modification of poly(ether sulfone) ultrafiltration membrane surface by self-assembly of $\mathrm{TiO}_{2}$ nanoparticles", Applied Surface Science, 249(1-4), 76-84.

Manohar, A., Krishnamoorthi, C., Naidu, K. C. B., \& Pavithra, C. (2019). "Dielectric, magnetic hyperthermia, and photocatalytic properties of $\mathrm{ZnFe}_{2} \mathrm{O}_{4}$ nanoparticles synthesized by solvothermal reflux method", Applied Physics A: Materials Science and Processing, 125(7), 477.

Moradihamedani, P., Ibrahim, N. A., Ramimoghadam, D., Yunus, W. M. Z. W., \& Yusof, N. A. (2014). "Polysulfone/zinc oxide nanoparticle mixed matrix membranes for $\mathrm{CO}_{2} / \mathrm{CH}_{4}$ separation", Journal of Applied Polymer Science, 131(16).

Nasrollahi, N., Vatanpour, V., Aber, S., \& Mahmoodi, N.M. (2018). "Preparation and characterization of a novel polyethersulfone (PES) ultrafiltration membrane modified with a $\mathrm{CuO} / \mathrm{ZnO}$ nanocomposite to improve permeability and antifouling properties", Separation and Purification Technology, 192(October 2017), 369-382.

Oliveira, F.C.C., Rossi, L.M., Jardim, R.F., \& Rubim, J. C. (2009). "Magnetic fluids based on $\gamma$-Fe2O3 and $\mathrm{CoFe} 2 \mathrm{O} 4$ nanoparticles dispersed in ionic liquids", Journal of Physical Chemistry C, 113(20), 8566-8572.

Reddy, D.H.K., \& Yun, Y.S. (2016). "Spinel ferrite magnetic adsorbents: Alternative future materials for water purification", Coordination Chemistry Reviews, 315, 90-111.

Safarpour, M., Vatanpour, V., \& Khataee, A. (2016). "Preparation and characterization of graphene oxide $/ \mathrm{TiO}_{2}$ blended PES nanofiltration membrane with improved antifouling and separation performance", Desalination, 393, 65-78.

Semblante, G.U., Tampubolon, S.D.R., You, S.J., Lin, Y.F., Chang, T.C., \& Yen, F.C. (2013). "Fouling reduction in membrane reactor through magnetic particles", Journal of Membrane Science, 435, 62-70.

Seyyed Shahabi, S., Azizi, N., Vatanpour, V., \& Yousefimehr, N. (2020). "Novel functionalized graphitic carbon nitride incorporated thin film nanocomposite membranes for highperformance reverse osmosis desalination", Separation and Purification Technology, 235, 116134.

Tyczkowski, J., Krawczyńska, M., \& Kazimierski, P. (2007). "Modification of Poly(propylene) Membranes for Electrochemical Cells by Low-Temperature Plasma Treatment", Plasma Processes and Polymers, 4(S1), S1086S1090.

Vatanpour, V., Faghani, S., Keyikoglu, R., \& Khataee, A. (2020). "Enhancing the permeability and antifouling properties of cellulose acetate ultrafiltration membrane by incorporation of $\mathrm{ZnO}$ graphitic carbon nitride nanocomposite", Carbohydrate Polymers, 11(7), 413.

Xie, T., Xu, L., Liu, C., \& Wang, Y. (2013). "Magnetic composite $\mathrm{ZnFe}_{2} \mathrm{O}_{4} / \mathrm{SrFe}_{12} \mathrm{O}_{19}$ : Preparation, characterization, and photocatalytic activity under visible light", Applied Surface Science, 273, 684-691.

Yang, Z., Wan, Y., Xiong, G., Li, D., Li, Q., Ma, C., Luo, H. (2015). "Facile synthesis of $\mathrm{ZnFe} 2 \mathrm{O} 4 /$ reduced graphene oxide nanohybrids for enhanced microwave absorption properties", Materials Research Bulletin, 61, 292-297.

Yu, H. Y., Xu, Z. K., Yang, Q., Hu, M. X., \& Wang, S. Y. (2006). "Improvement of the antifouling characteristics for polypropylene microporous membranes by the sequential photoinduced graft polymerization of acrylic acid", Journal of Membrane Science, 281(1-2), 658-665.

Zareei, F., \& Hosseini, S.M. (2019). "A new type of polyethersulfone based composite nanofiltration membrane decorated by cobalt ferrite-copper oxide nanoparticles with enhanced performance and antifouling property", Separation and Purification Technology, 226, 48-58.

Zhang, D., Karkooti, A., Liu, L., Sadrzadeh, M., Thundat, T., Liu, Y., \& Narain, R. (2018). "Fabrication of antifouling and antibacterial polyethersulfone (PES)/cellulose nanocrystals (CNC) nanocomposite membranes", Journal of Membrane Science, 549, 350-356.

Zinadini, S., Rostami, S., Vatanpour, V., \& Jalilian, E. (2017). "Preparation of antibiofouling polyethersulfone mixed matrix NF membrane using photocatalytic activity of $\mathrm{ZnO} / \mathrm{MWCNTs}$ nanocomposite", Journal of Membrane Science, 529, 133-141.

Zinadini, S., Zinatizadeh, A.A., Rahimi, M., Vatanpour, V., \& Zangeneh, H. (2014a). "Preparation of a novel antifouling mixed matrix PES membrane by embedding graphene oxide nanoplates", Journal of Membrane Science, 453, 292-301.

Zinadini, S., Zinatizadeh, A. A., Rahimi, M., Vatanpour, V., \& Zangeneh, H. (2014b). Preparation of a novel antifouling mixed matrix PES membrane by embedding graphene oxide nanoplates. Journal of Membrane Science, 453, 292-301. 